\title{
3D-QSAR and Molecular Docking Approaches for the Identification of Phyto-Inhibitors of Hsp90
}

\author{
Damilohun Samuel Metibemu 1,*(iD) \\ 1 Department of Biochemistry, Adekunle Ajasin University, Akungba-Akoko, Ondo State, Nigeria; \\ damilohun.metibemu@aau.edu.ng (D.S.M.); \\ * Correspondence: damilohun.metibemu@aaua.edu.ng (D.S.M.);
}

Scopus Author ID 57205344377

Received: 8.04.2021; Revised: 7.08.2021; Accepted: 14.08.2021; Published: 12.09.2021

\begin{abstract}
Inhibition of Hsp90 disrupts the Hsp90 client protein complex, resulting in its breakdown. Phytochemicals from reported anticancer plants were screened against the orthosteric site of Hsp90. The lead compounds were subjected to the Lipinski rule of five to evaluate their drug-likeness. ThreeDimensional Quantitative Structure-Activity Relationships (3D-QSAR), a mathematical model for the inhibition of Hsp90, was also derived. The lead compounds are guaiol from Cannabis sativa, actinidine from Anacadium occidentale, and choline from Tinospora cordifolia with docking scores of $11 \mathrm{kcal} / \mathrm{mol},-12.1 \mathrm{kcal} / \mathrm{mol}$, and $-10.8 \mathrm{kcal} / \mathrm{mol}$, respectively. The 3D-QSAR model generated is robust and thoroughly validated with a correlation coefficient $\mathrm{R}$ of 0.94 and $\mathrm{R}^{2}$ of 0.950 . Actinidine, choline and, guaiol are novel and potent inhibitors of Hsp90. They form interactions with key amino acid residues within the Hsp90 orthosteric site.
\end{abstract}

Keywords: cancer; Hsp90; molecular docking; 3D-QSAR.

(C) 2021 by the authors. This article is an open-access article distributed under the terms and conditions of the Creative Commons Attribution (CC BY) license (https://creativecommons.org/licenses/by/4.0/).

\section{Introduction}

Molecular chaperones help assemble and correct the folding of polypeptide chains into their oligomeric structures [1]. Heat-shock proteins (Hsps) are made up of molecular chaperones that are upregulated in stressful conditions to avoid denaturation and inappropriate aggregation of proteins to maintain protein homeostasis [2]. Hsps also play pivotal roles in non-stressful conditions, in scores of housekeeping functions, from signal transduction, proliferation, metastasis, protein trafficking, and apoptosis [2]. The 90kDa heat shock protein (Hsp90) is an ATP-dependent molecular chaperone that malignant cells use to support activated oncoproteins [3]. Therefore, its implications on cancer have led to the emergence of its being considered a promising target for anticancer drugs. Though originally viewed with pessimism, Hsp90 inhibitors are now pursued by the pharmaceutical industry [3]. It has been observed that Hsp90 is over-expressed in many cancers.

Irrespective of the advances in cancer treatments, developing safe and effective antineoplastic compounds remains a great challenge [4]. Plants and natural products continue to be employed in the management of cancer [5]. A good number of cancer drugs are from plants and natural products [6]. The failures coupled with the associated side effects of conventional neoplastic drugs continue to gather interest in plants as alternatives in neoplastic management. Epidemiological studies revealed the consumption of natural products decreases 
the risk of cancer [7]. Many phytochemicals have been reported from medicinal plants to possess anticancer properties [8-10].

In the present study, phytochemicals from reported anticancer plants, Cannabis sativa, Anacadium occidentale, Spondias mombin, Tinospora cordifolia, and Zingiber officinale were screened against the orthosteric site of Hsp90. The lead compounds were subjected to the Lipinski rule and ADME (absorption, distribution, metabolism, and excretion) screening to determine their drug-likeness. A 3D-QSAR model for the inhibition of Hsp90 was also derived. Molecular interactions of the leads within the orthosteric site of Hsp90 were also assessed.

\section{Materials and Methods}

\subsection{Protein preparation for docking.}

The 3D crystallized conformation of the Hsp90 was downloaded from the Protein Data Bank (PDB) repository with the PDB ID of 2QG2 and a crystallographic resolution of $1.8 \AA$. The protein was viewed with Pymol. Water molecules were removed from the protein. The protein's active site and the grid map were generated with Pymol AutoDock Vina, $X=3.59, Y=$ 33.95, $\mathrm{Z}=24.51[11]$.

\subsection{Generation of ligand library.}

A total of 400 phytochemicals characterized by six different anticancer plants; Tinospora cordifolia, Anacadium occidentale, Cannabis sativa, Zingiber officinale, Spondias mombim, and Oscimum gratisimum were obtained from the literature. The 2D structures of the ligands were downloaded in the SDF format from the NCBI PubChem database [12]. The structures of the compounds generated from each plant were catenated, and the 3D-pdb and pdbqt format of the ligands were generated using the babel and lig prep commands, respectively.

Command line for catenation

$C a t * . s d f>A . s d f$

Command line for converting to $p d b$

babel $*$ A.sdf output.pdb $-h-r-m-$-gen $3 D$

Command line for converting to pdbqt

For $i$ in $\{1 . . n\}$; do lig_prep -l output.pdb output\$[i] pdbqt; done

Where A rep. the name of compound

\subsection{Molecular docking.}

The protein-ligand docking was carried out with Autodock Vina [11]. The co-crystallized ligand was extracted, and the water molecules were removed. The phytochemicals were docked into the exact Hsp90 catalytic site as occupied by the cocrystallized compound. Command lines in AutoDock Vina were used to carry out multiple docking of the phytochemicals. Command-line for docking.

For $i$ in $\{1 \ldots n\}$; do vina -- config name. vinaconfig.txt-ligand name $\$\{i\} p d b q t$-out $\$\{i\}$.out $-\log \$[i]$.out $-\log \$[i] . \log$; done 


\subsection{Validation of docking results.}

The docking scores were validated by determining the correlation between $\mathrm{pIC}_{50}$ values of known inhibitors of Hsp90 against their corresponding docking scores. The Hsp90 domain receptor sequences obtained from PubMed were blasted on the Chembl database (www.ebiac.uk/chembl). A total of 89 known inhibitors of Hsp90 with their corresponding $\mathrm{pIC}_{50}$ were downloaded in text format and converted to SDF format by Data Warrior version 2. These were docked into Hsp90 orthosteric site. Positive correlation was set $\mathrm{P}<0.01$. The deviation of the lead compounds and the co-crystallized compound from the active site of Hsp90 was also evaluated.

\subsection{Lipinski and ADME.}

Lipinski's rule of five is a rule of thumb for predicting the drug-likeness and orally active compounds. Poor absorption or permeation is more likely when there are more than 5 H-bond donors, $10 \mathrm{H}$-bond acceptors, molecular weight (MWT) greater than 500, and the calculated $\log \mathrm{P}(\mathrm{C} \log \mathrm{P})$ greater than 5 (or MlogP>4.15) ([13]. The rule of five further describes molecular properties, which are vital to ascertain the pharmacokinetics of compounds. The lead compounds were subjected to the Lipinski rule of five to quantify their drug-likeness. The Mavin Viewer software was used to establish the conformity of lead compounds to the rule of five. The number of rotatable bonds and polar surface area, which are known to discriminate between orally active compounds and those that are not, for a large data set of compounds [14] were also generated. Compounds with 10 or fewer rotatable bonds and polar surface area equal to or less than $140 \AA^{2}$ have good oral bioavailability [14].

\subsection{Quantitative structure-activity relationship (QSAR).}

\subsubsection{Data collection and descriptor calculation.}

The bioassay $\mathrm{IC}_{50}$ data for $\mathrm{Hsp} 90$ was downloaded from the Chembl database (http://ebi.ac.uk). The 'Babel' was used to convert the compounds to the PDB format. Molecular descriptors were generated with the chemistry development kit (CDK).

\subsubsection{Data pre-treatment}

The pre-treatment of the bioassay $\mathrm{IC}_{50}$ data was carried with the V-WSP algorithm [15]. This helps to remove co-linearity among the descriptors.

\subsubsection{Data set division: training and test sets.}

The data set of 100 Hsp90 inhibitors obtained was split into the training set and test set using the Kennard Stone algorithm [16]. The data set was separated into $70 \%$ training and $30 \%$ test sets.

2.6.4 Genetic algorithm and multiple linear regression.

A genetic algorithm (GA) was used for model generation and selecting significant variables (descriptors) in the training set. Multiple Linear Regression (MLR) in IBM SPSS 
(Statistical Package for the Social Sciences ) 21 was used for statistical computing and also to confirm the model from GA.

\section{Results and Discussion}

\subsection{Molecular docking.}

The docking score of the co-crystallized ligand (A91) 3-(\{2-[(2-Amino-6-methyl-4pyrimidinyl)ethynyl]benzyl \}amino)-1,3-oxazol-2(3H)-one against the catalytic site of Hsp9 [17], $-10.8 \mathrm{kcal} / \mathrm{mol}$ was used as the cut off for the selection of lead compounds. Molecular docking of phytochemicals from Tinospora cordifolia, Anacadium officianale, Spondias mombim, Oscimum gratissimum, Cannabis sativa and Zingiber officianale against Hsp90 orthosteric site, generated 3 hits; choline from Tinospora cordifolia plant, guaiol from Cannabis sativa plant and actinidine from Anacadium occidentale plant with docking scores of $-10.8 \mathrm{kcal} / \mathrm{mol},-11 \mathrm{kcal} / \mathrm{mol}$ and $-12.1 \mathrm{kcal} / \mathrm{mol}$ respectively (Table S1). It should be noted that both choline and guaiol have been reported to possess anticancer properties [18-20].

\subsection{Validation of docking scores.}

The analysis of the correlation coefficient of the $\mathrm{pIC}_{50}$ of experimentally determined 89 inhibitors of Hsp90, obtained from chembl ((https://www.ebi.ac.uk/chembl/) and their corresponding docking scores show there is a positive correlation of .667 between $\mathrm{pIC}_{50}$ and their docking scores at $\mathrm{p}<0.01$ (Table S2 and Figure S1). There is no deviation of the lead compounds and the co-crystallized compound from the orthosteric site of Hsp90 (Figure 1). All these show that the molecular docking results are correct and can predict the inhibitory potentials of compounds with Hsp90.

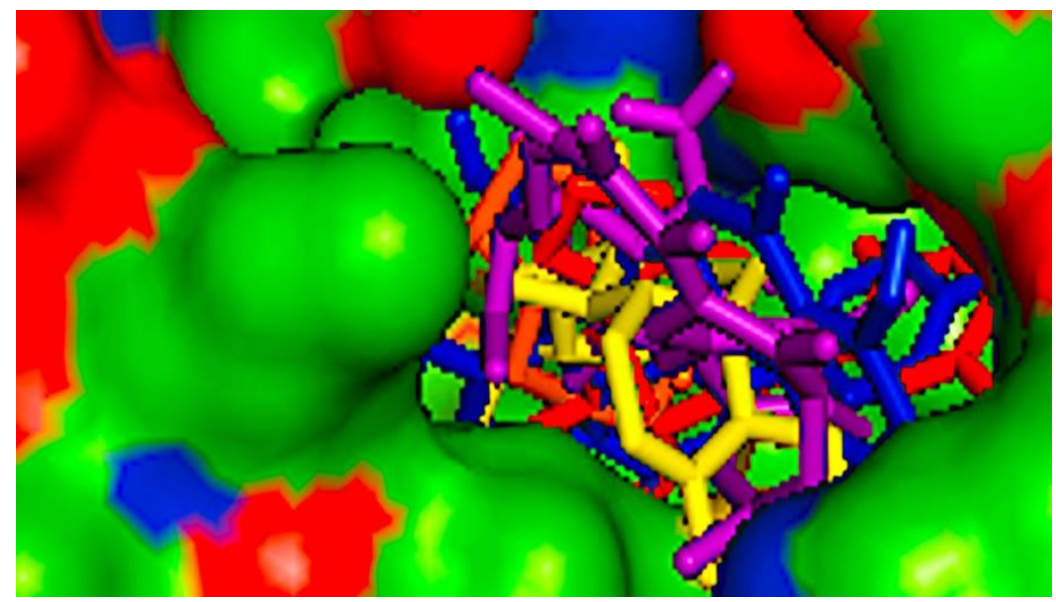

Figure 1. Binding pocket of the Hsp90 with actinidine, (yellow) choline (purple), guaiol (orange), and the cocrystallized ligand (red).

\subsection{Lipinski and ADME screening.}

According to Lipinski et al., 2001 [13], for a drug to be orally active, the number of hydrogen bond acceptors should be $\leq 10$, Hydrogen bond donor $\leq 5$, the number of rotatable bonds should be $\leq 10$, the partition coefficient (XLogP) should be $\leq 5$, the molecular weight should be $<500$ and the polar surface area should be $<140 \AA^{2}$. All the 3 hits generated obey Lipinski's rule (Table S3). 
3.4. The QSAR analysis.

Quantitative structure-activity relationship (QSAR) is a statistical procedure, which seeks to find a significant correlation between structure and function. The training set used in this case was seventy known inhibitors of Hsp90. Genetic algorithm and IBM SPSS software for statistical computing were used for the MLR analysis and generation of the model.

Table 1. Model Summary; Showing R (the multiple correlation coefficients) value R square (the coefficient of

\begin{tabular}{l|c|c}
\multicolumn{3}{c}{ determination) value, Adjusted R square, and Durbin Watson value. } \\
\multicolumn{1}{c}{ R Square } & Adjusted R Square \\
\hline .974 & .950 & .925 \\
\hline a. Predictors: (Constant), C1SP2 & \\
\hline b. Predictors: (Constant), C1SP2, WTPT-5, Weta1.unity, C3SP2, FPSA-1, SCH-7, khs.sCH3, WK.unity, ATSc1, SPC-4 \\
\hline c. Dependent Variable: P
\end{tabular}

There is a very high positive Pearson Correlation, R, 0.974 (Table 1). This indicates a high correlation between the dependent variable $\left(\mathrm{pIC}_{50}\right)$ and the independent variables. The $\mathrm{R}$ square value of 0.950 demonstrates the QSAR model could account for $95 \%$ of the variation of the pIC $\mathrm{I}_{50}$. The adjusted $\mathrm{R}^{2}$ shows how the model generalizes, that is, external validation of the model. The adjusted $R^{2}$ is close to the $R^{2}$ value (the difference between the $R^{2}$ value and the adjusted $\mathrm{R}^{2}$ value is 0.025 ); this signifies that the model experiences an insignificant $2.5 \%$ shrinkage in predicting external $\mathrm{pIC}_{50}$. The closeness of the adjusted $\mathrm{R}^{2}$ value to the $\mathrm{R}^{2}$ value shows that the cross validity of the model is excellent. Figure S2 shows homoscedasticity; the variables are very close to the line; hence, the model is unbiased. A plot of the observed $\mathrm{pIC}_{50}$ and the predicted $\mathrm{pIC}_{50}$ showed a very strong positive correlation, $\mathrm{R}^{2} 0.950$. This demonstrates that the model has strong predictability, robustness, and validity (Figure 2, Table S4).

\subsubsection{Generation of QSAR Model.}

The QSAR model (equation 1) generated from the Genetic algorithm (GA) is the same as obtained from the MLR in IBM SPSS. This validated the accuracy of the model (1). $\mathrm{pIC}_{50}=(15.268)+0.669 *$ CISP2 $)+(-3.726 *$ Weta1. un $)+(0.098 *$ WTPT -5$)+$ $(-0.178 * k$ khs. Sch 3$)+(-4.159 *$ SCH -7$)+(-1.846 *$ ATSC 1$)+(-4.58 *$ FPSA $1)+(6.563 *$ WK. Unity $)+(0.85 * \mathrm{C} 3 \mathrm{SP} 2)+(0.58 * \mathrm{SPC}-4) \ldots \ldots \ldots . .1$

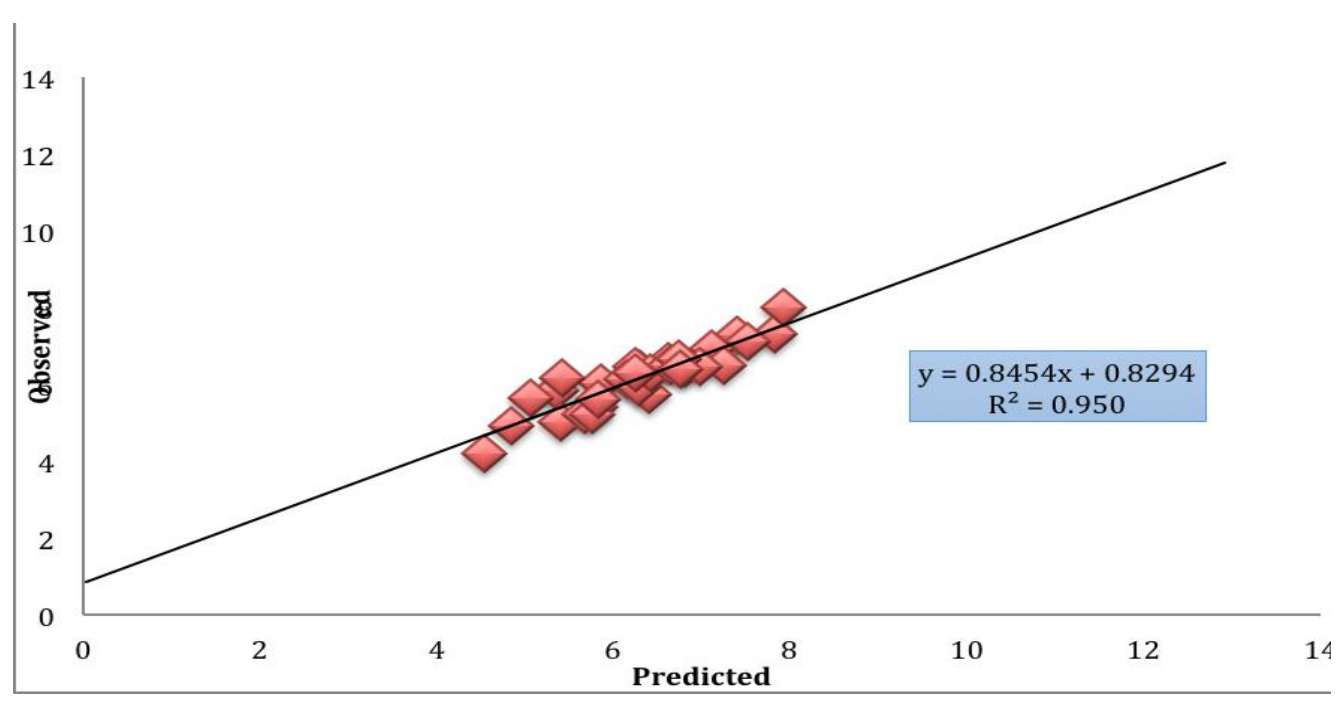

Figure 2. Observed $\mathrm{pIC}_{50}$ values against the predicted $\mathrm{pIC}_{50}$ Values. 
3.5. Molecular docking interactions of the leads and the co-crystallized compound.

The leads formed various interactions with cogent amino acids residues in the orthosteric site of Hsp90 (Figures 3-6, Table 2). Actinidine forms three hydrophobic interactions with Leu-103, Leu-107, Trp-162, and one pie interaction with Phe-138 (Figure 4). Choline forms two hydrogen bond interactions with Leu-48 and Asp-93 and one salt bridge interaction with Asp-93 (Figure 5). Guaiol forms only two hydrophobic interactions with Leu107, Phe-138 (Figure 6). The co-crystallized forms three hydrophobic interactions with Leu48, Leu10, and Phe-138, two pie stacking interactions with Phe138, and Trp-162, one salt bridge interaction Asp-93, two hydrogen bond interactions with Tyr-139 and Tyr-184 (Figure $3)$. The extensive interactions of the co-crystallized, 3-(\{2-[(2-Amino-6-methyl-4-pyrimidinyl) ethynyl] benzyl $\}$ amino)-1,3-oxazol-2(3H)-one within the Hsp90 orthosteric site is probably responsible for its inhibitory potentials on Hsp90 [17]. The topmost hit, actinidine, shares some remarkable amino acids residues with the co-crystallized ligand, Leu-107, and Phe-138, hence its probable high binding energy. Choline forms two hydrogen bonds and one salt bridge interactions with the amino acid residues within the Hsp90 orthosteric site. In addition, guaiol share similar hydrophobic interactions with the co-crystallized, Leu-107 and Phe-138, which might be responsible for its inhibition of Hsp90.

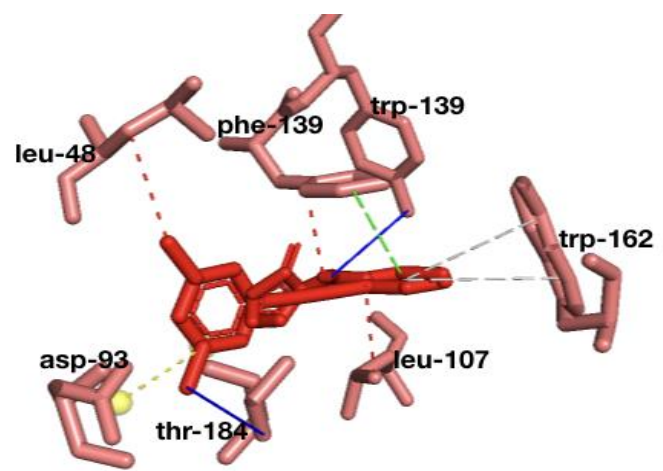

Figure 3. A. Interactions of the co-crystallized ligand, 3-(\{2-[(2-Amino-6-methyl-4-

pyrimidinyl)ethynyl]benzyl \}amino)-1,3-oxazol-2(3H)-one (red) with key residues at the catalytic site of Hsp90, the dotted red lines represent the hydrophobic interactions, the blue lines represent hydrogen bonds interactions, the yellow line represents salt bridge while the green and grey lines represent pie stacking.

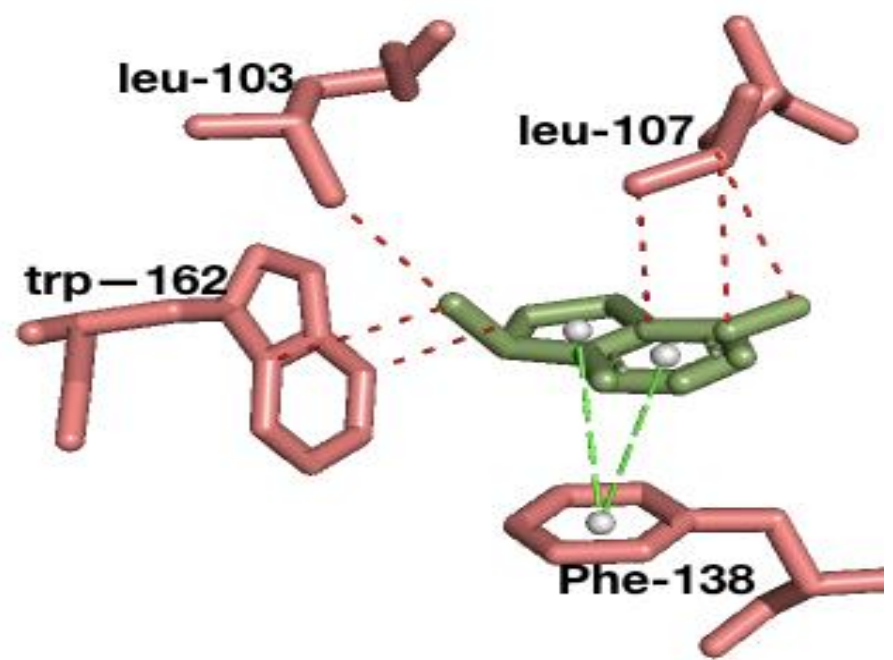

Figure 4. Interactions of actinidine (smudge-green) with key residues at the catalytic site of Hsp90, the dotted red lines represent the hydrophobic interactions while the green line represents pie stacking. 


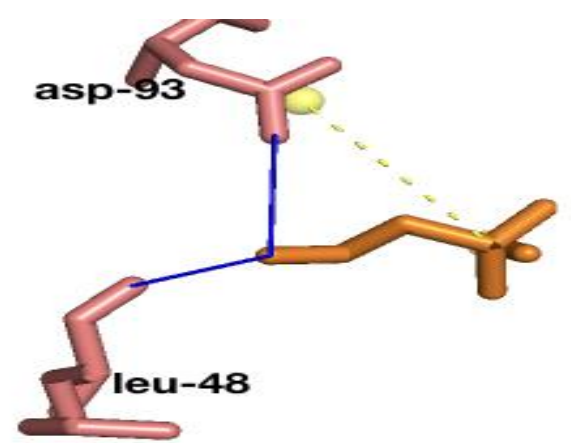

Figure 5. Interactions of choline (orange) with key residues at the catalytic site of Hsp90, the blue lines represent the hydrogen bond interactions while the dotted yellow line represents the salt bridge.

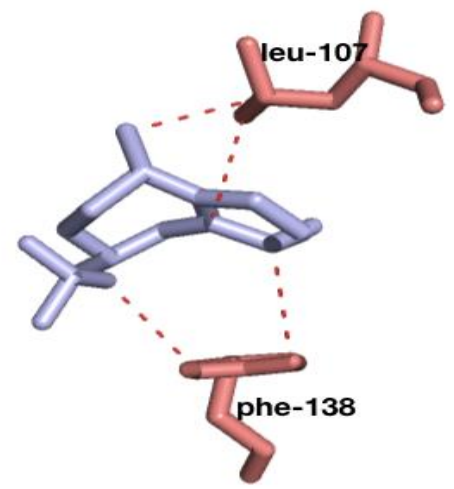

Figure 6. Interactions of guaiol (light blue) with key residues at the catalytic site of Hsp90, the dotted red lines represent the hydrophobic interactions.

Table 2. Molecular Interactions of the Hits within the Orthosteric site of Hsp90.

\begin{tabular}{l|l|l|l|l} 
& Hydrophobic Interaction & $\pi$ Stacking & Salt Bridges & Hydrogen Bonds \\
\hline Co-crystallized-Hsp90 & Leu-48, Leu107, Phe-138 & Phe138, Trp-162 & Asp-93 & Tyr-139, Tyr-184 \\
\hline Actinidine-Hsp90 & Leu-103, Leu-107, Trp-162 & Phe-138 & & \\
\hline Choline-Hsp90 & & & Asp-93 & Leu-48, Asp-93 \\
\hline Guaiol-Hsp90 & Leu-107, Phe-138 & & &
\end{tabular}

\section{Conclusions}

Hsp90 is a therapeutic target for the treatment of cancer. A thoroughly validated and robust model for the inhibition of Hsp90 is derived herein. Molecular docking analysis revealed choline, actinidine, and guaiol as potential novel inhibitors of Hsp90. They form critical interactions with key residues that are pertinent to the inhibition of Hsp90. They are drug-like inhibitors of Hsp90. The mechanisms of their inhibitory potentials on Hsp90 should be exploited.

\section{Funding}

This research received no external funding.

\section{Acknowledgments}

The author acknowledges the effort of Dr. O.E. Oyeneyin towards the research.

\section{Conflicts of Interest}

The authors declare no conflict of interest. 


\section{References}

1. Webster, J.M.; Darling, A.L.; Uversky, V.N.; Blair, L.J. Small Heat Shock Proteins, Big Impact on Protein Aggregation in Neurodegenerative Disease. Frontiers in Pharmacology 2019, 10, https://doi.org/10.3389/fphar.2019.01047.

2. Scieglinska, D.; Krawczyk, Z.; Sojka, D.R.; Gogler-Pigłowska, A. Heat shock proteins in the physiology and pathophysiology of epidermal keratinocytes. Cell Stress and Chaperones 2019, 24, 1027-1044, https://doi.org/10.1007/s12192-019-01044-5.

3. Jego, G.; Hermetet, F.; Girodon, F.; Garrido, C. Chaperoning STAT3/5 by Heat Shock Proteins: Interest of Their Targeting in Cancer Therapy. Cancers 2020, 12, https://doi.org/10.3390/cancers12010021.

4. Pucci, C.; Martinelli, C.; Ciofani, G. Innovative approaches for cancer treatment: current perspectives and new challenges. Ecancermedicalscience 2019, 13, https://doi.org/10.3332/ecancer.2019.961.

5. Chota, A.; George, B.P.; Abrahamse, H. Potential Treatment of Breast and Lung Cancer Using Dicoma anomala, an African Medicinal Plant. Molecules 2020, 25, https://doi.org/10.3390/molecules25194435.

6. Mintah, S.O.; Asafo-Agyei, T.; Archer, M.A.; Junior, P.A. A.; Boamah, D.; Kumadoh, D.; Appiah, A.; Ocloo, A.; Boakye, Y.W.; Agyare, C. Medicinal plants for treatment of prevalent diseases. Pharmacogn. Med. Plants. 2019, 1-19, https://doi.org/10.5772/intechopen.82049.

7. Key, T.J.; Bradbury, K.E.; Perez-Cornago, A.; Sinha, R.; Tsilidis, K.K.; Tsugane, S. Diet, nutrition, and cancer risk: what do we know and what is the way forward? BMJ 2020, 368, https://doi.org/10.1136/bmj.m511.

8. Akinloye, O.; Akinloye, D.; Lawal, M.; Mujidat; Shittu, T.; Metibemu, D.S. Terpenoids from Azadirachta indica are potent inhibitors of Akt: Validation of the anticancer potentials in hepatocellular carcinoma in male Wistar rats. Journal of Food Biochemistry 2020, 45, https://doi.org/10.1111/jfbc.13559.

9. Metibemu, D.S.; Akinloye, O.A.; Akamo, A.J.; Okoye, J.O.; Ojo, D.A.; Morifi, E.; Omotuyi, I.O. Carotenoid isolates of Spondias mombin demonstrate anticancer effects in DMBA-induced breast cancer in Wistar rats through X-linked inhibitor of apoptosis protein (XIAP) antagonism and anti-inflammation. Journal of Food Biochemistry 2020, 44, https://doi.org/10.1111/jfbc.13523.

10. Metibemu, D.S.; Akinloye, O.A.; Akamo, A.J.; Okoye, J.O.; Ojo, D.A.; Morifi, E.; Omotuyi, I.O. VEGFR-2 kinase domain inhibition as a scaffold for anti-angiogenesis: Validation of the anti-angiogenic effects of carotenoids from Spondias mombin in DMBA model of breast carcinoma in Wistar rats. Toxicology Reports 2021, 8, 489-498, https://doi.org/10.1016/j.toxrep.2021.02.011.

11. Trott, O.; Olson, A.J. AutoDock Vina: improving the speed and accuracy of docking with a new scoring function, efficient optimization, and multithreading. J. Comput. Chem. 2010, 31, 455-461, https://doi.org/10.1002/jcc.21334.

12. Kim, S.; Thiessen, P.A.; Bolton, E.E.; Chen, J.; Fu, G.; Gindulyte, A.; Han, L.; He, J.; He, S.; Shoemaker, B.A.; Wang, J.; Yu, B.; Zhang, J.; Bryant, S.H. PubChem Substance and Compound databases. Nucleic Acids Res. 2015, 44, D1202-13.

13. Lipinski, C.A.; Lombardo, F.; Dominy, B.W.; Feeney, P.J. Experimental and computational approaches to estimate solubility and permeability in drug discovery and development settings. Adv. Drug Deliv. Rev. 1997, 23, 3-25, https://doi.org/10.1016/s0169-409x(00)00129-0.

14. Veber, D.F.; Johnson, S.R.; Cheng, H.Y.; Smith, B.R.; Ward, K.W.; Kopple, K.D. Molecular properties that influence the oral bioavailability of drug candidates. J. Med. Chem. 2002, 45, 2615-2623, https://doi.org/10.1021/jm020017n.

15. Ballabio, D.; Consonni, V.; Mauri, A.; Claeys-Bruno, M.; Sergent, M.; Todeschini, R. A novel variable reduction method adapted from space-filling designs. Chemom. Intell. Lab. Syst. 2014, 136, 147-154, https://doi.org/10.1016/j.chemolab.2014.05.010.

16. Todd, M.M.; Arten, P.; Douglas, M.Y.; Muratov, E.N.; Golbraikh, A.; Zhu, H.; Tropsha, A. Does Rational Selection of Training and Test Sets Improve the Outcome of QSAR Modeling? J. Chem. Inf. Model. 2012, 52, 2570-2578, https://doi.org/10.1021/ci300338w.

17. Huth, J.R.; Park, C.; Petros, A.M.; Kunzer, A.R.; Wendt, M.D.; Wang, X.; Lynch, C.L.; Mack, J.C.; Swift, K.M.; Judge, R.A.; Chen, J.; Richardson, P.L.; Jin, S.; Tahir, S.K.; Matayoshi, E.D.; Dorwin, S.A.; Ladror, U.S.; Severin, J.M.; Walter, K.A.; Bartley, D.M.; Fesik, S.W.; Elmore, S.W.; Hajduk, P.J. Discovery and Design of Novel HSP90 Inhibitors Using Multiple Fragment-based Design Strategies. Chemical Biology \& Drug Design 2007, 70, 1-12, https://doi.org/10.1111/j.1747-0285.2007.00535.x.

18. Salehi, B.; Fokou, P.V.; Yamthe, L.R.; Tali, B.T.; Adetunji, C.O.; Rahavian, A.; Mudau, F.N.; Martorell, M.; Setzer, W.N.; Rodrigues, C.F.; Martins, N.; Cho, W.C.; Sharifi-Rad, J. Phytochemicals in Prostate Cancer: From Bioactive Molecules to Upcoming Therapeutic Agents. Nutrients 2019, 11, https://doi.org/10.3390/nu11071483.

19. Yang, Q.; Wu, J.; Luo, Y.; Huang, N.; Zhen, N.; Zhou, Y.; Sun, F.; Li, Z.; Pan, Q.; Li, Y. (-)-Guaiol regulates RAD51 stability via autophagy to induce cell apoptosis in non-small cell lung cancer. Oncotarget. 2016, 7 , 62585-62597, https://doi.org/10.18632/oncotarget.11540.

20. Tomko, A.M.; Whynot, E.G.; Ellis, L.D.; Dupré, D.J. Anti-Cancer Potential of Cannabinoids, Terpenes, and Flavonoids Present in Cannabis. Cancers 2020, 127, https://doi.org/10.3390/cancers12071985. 


\section{Supplementary Data}

Table S1. Docking scores of some of the phytochemicals docked into the active site of Human Hsp90.

\begin{tabular}{l|l|l|l|l|l}
$\begin{array}{l}\text { Phytochemicals } \\
\text { Cannabis sativa }\end{array}$ & $\begin{array}{c}\text { Docking } \\
\text { Score }\end{array}$ & $\begin{array}{l}\text { Phytochemicals } \\
\text { Anacardium occidentale }\end{array}$ & $\begin{array}{c}\text { Docking } \\
\text { Score }\end{array}$ & $\begin{array}{l}\text { Phytochemicals } \\
\text { Tinospora cordifolia }\end{array}$ & $\begin{array}{c}\text { Docking } \\
\text { score }\end{array}$ \\
\hline Guaiol & -11 & Actinidine & -12.1 & Choline & -10.8 \\
\hline Cycloartenol & -10.7 & 3-o-methylcyanidinhexoside & -10.8 & Bergenin & -10.5 \\
\hline Stigmasterol & -10.7 & chlorogenic acid & -10.7 & Aporphine & -10.4 \\
\hline Cannabichromene & -10.5 & 2,3-Dihydroxybenzoic acid & -10.6 & Ecdysterone & -10.4 \\
\hline Cannabielsoin & -10.3 & Palbociclib & -10.6 & makisterone A & -10.4 \\
\hline Cephradine & -10.3 & Quercetin-3-O-rhamnoside & -10.5 & beta ecdysterone & -10.1 \\
\hline Chrysin & -10.3 & Rutin & -10.4 & Magnoflorine & -10.1 \\
\hline alpha phellandrene & -10.2 & Corydaline & -10.3 & palmatoside C & -10 \\
\hline Luteolin & -10 & Berberine & -10.2 & Lysicamine & -9.8 \\
\hline Malvidin & -9.8 & (-)-Epigallocatechin & -9.9 & palmatoside B & -9.8
\end{tabular}

Table S2. Correlation coefficient Analysis.

\begin{tabular}{|c|c|c|c|c|}
\hline & & & & $\mathrm{pIC}_{50}$ \\
\hline \multirow[t]{7}{*}{ Docking score } & $\begin{array}{l}\text { Correlation } \\
\text { Coefficient }\end{array}$ & & & $.660^{* * *}$ \\
\hline & Sig. (2-tailed) & & & 0 \\
\hline & $\mathrm{N}$ & & & 89 \\
\hline & Bootstrap $^{b}$ & Bias & & -0.008 \\
\hline & & Std. Error & & 0.07 \\
\hline & & $\begin{array}{l}\mathrm{BCa} \\
\text { Confidence Interval }\end{array}$ & Lower & 0.515 \\
\hline & & & Upper & 0.777 \\
\hline
\end{tabular}

** shows there is significant positive correlation at $\mathrm{p}<0.01$

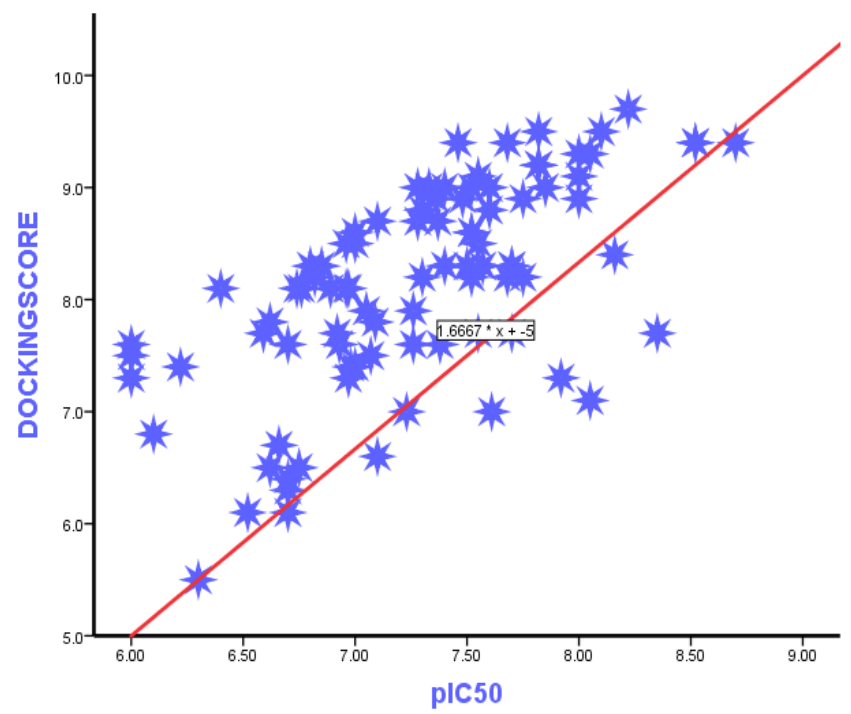

Figure S1. Graph of Docking Scores Versus pIC . $_{50}$

Table S3. Determination of the Drug-likeness of the hit compounds.

\begin{tabular}{l|l|l|l|l|l|l|l} 
Plants & Hit name & HBA $\leq \mathbf{1 0}$ & HBD $\leq \mathbf{5}$ & $\mathbf{M W} \leq \mathbf{5 0 0}$ & PSA & $\mathbf{X L o g p}$ & $\mathbf{n R O T b} \leq \mathbf{5}$ \\
\hline Tinospora & Choline & 1 & 1 & 104.173 & 20.23 & -0.4 & 2 \\
\hline Cannabis & Guaiol & 1 & 1 & 222.372 & 20.23 & 3.1 & 1 \\
\hline Anacadium & Actinidine & 1 & 0 & 147.221 & 12.89 & 2.4 & 0 \\
\hline Standarddrug & Geldanamycin & 9 & 3 & 560.644 & 163.48 & 2 & 5
\end{tabular}

NOTE;

HBA means hydrogen bond acceptor

HBD means hydrogen bond donor

MW means molecular weight

PSA means polar surface area

nROTb means no. of rotatable bonds

XLogP means Octanol-water partition coefficient 


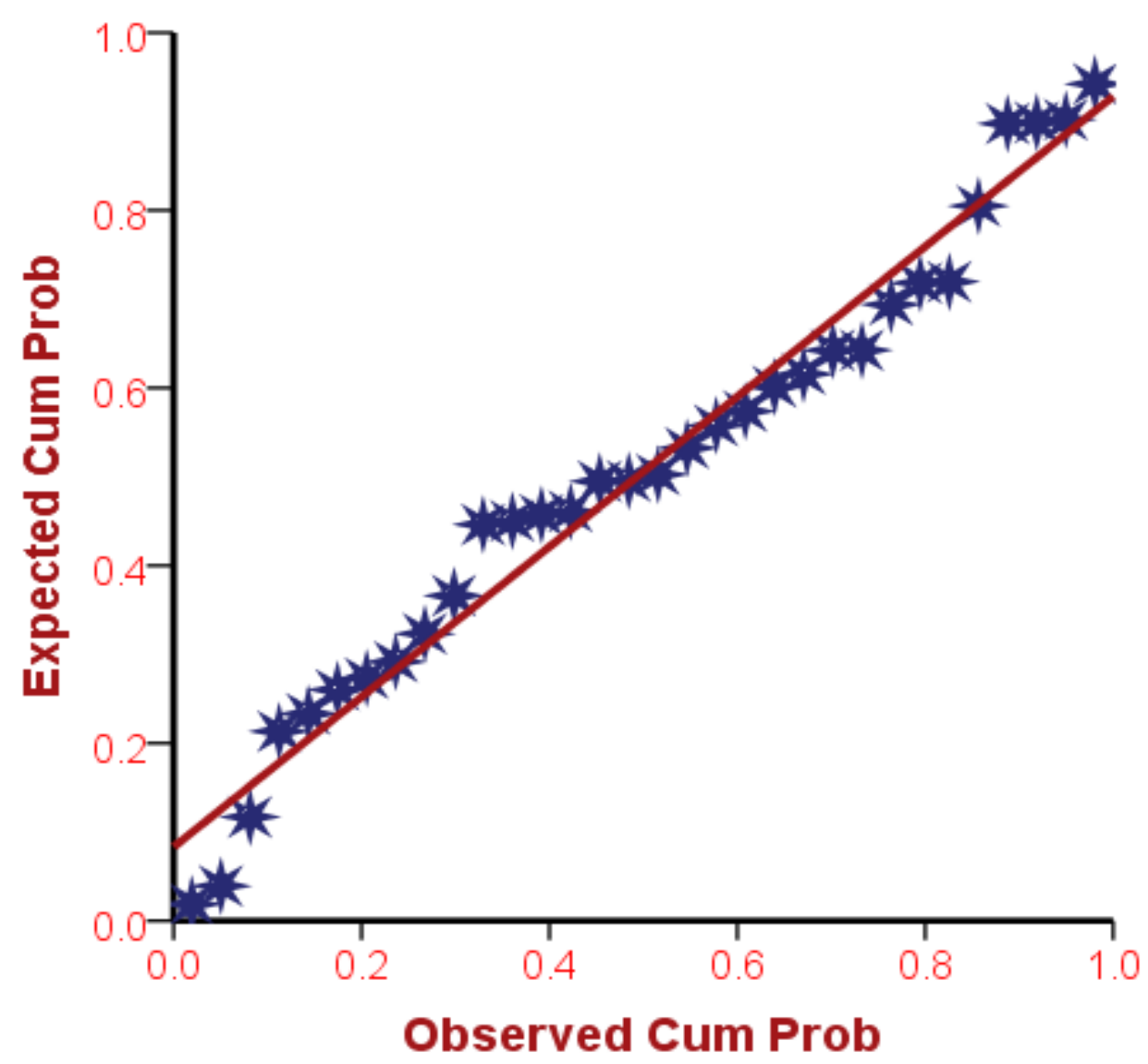

Figure S2. Normal distribution plot of the model.

Table S4. The $\mathrm{pIC}_{50}$ of the observed and predicted values from some of the compounds in the training set.

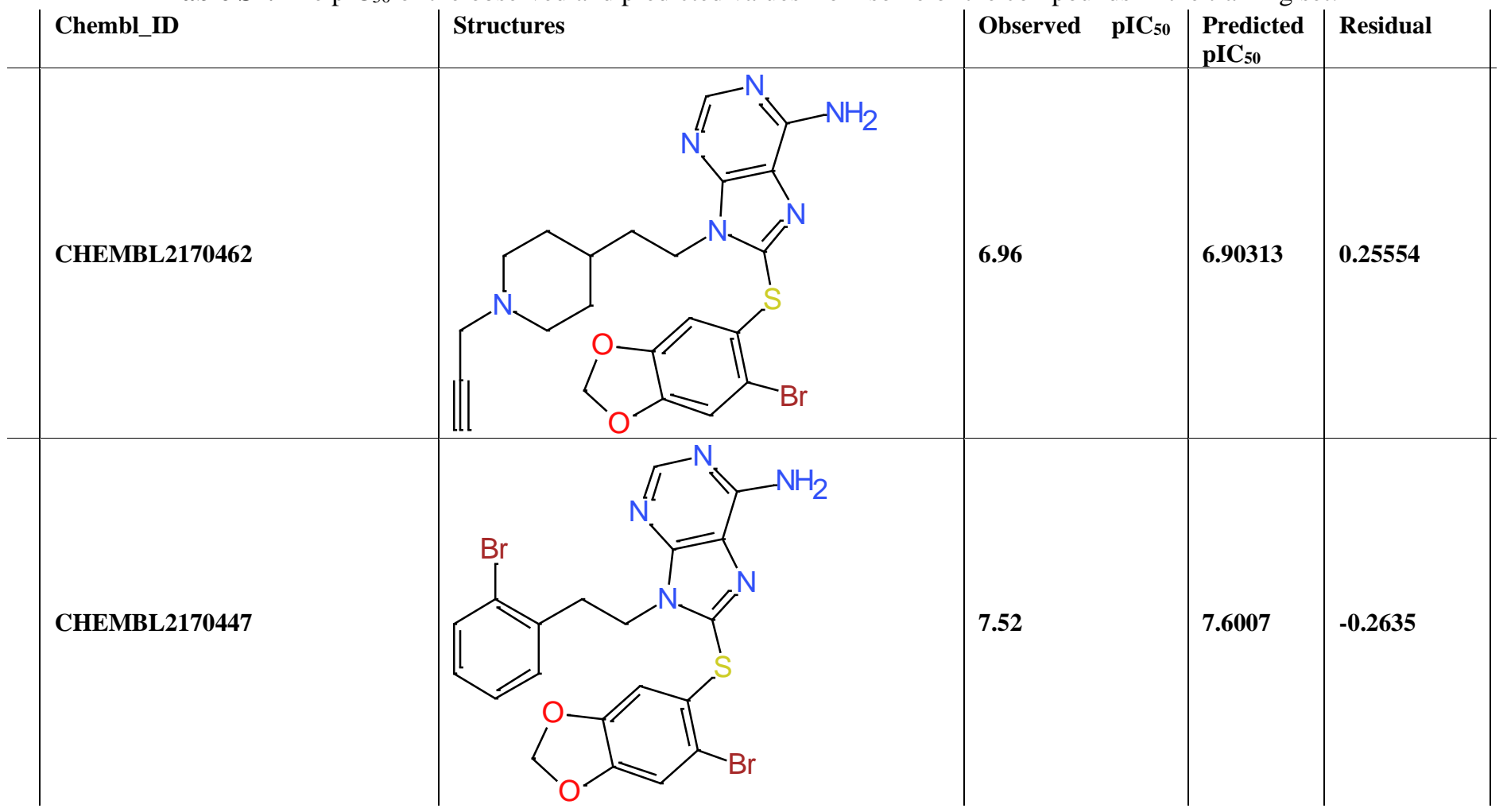




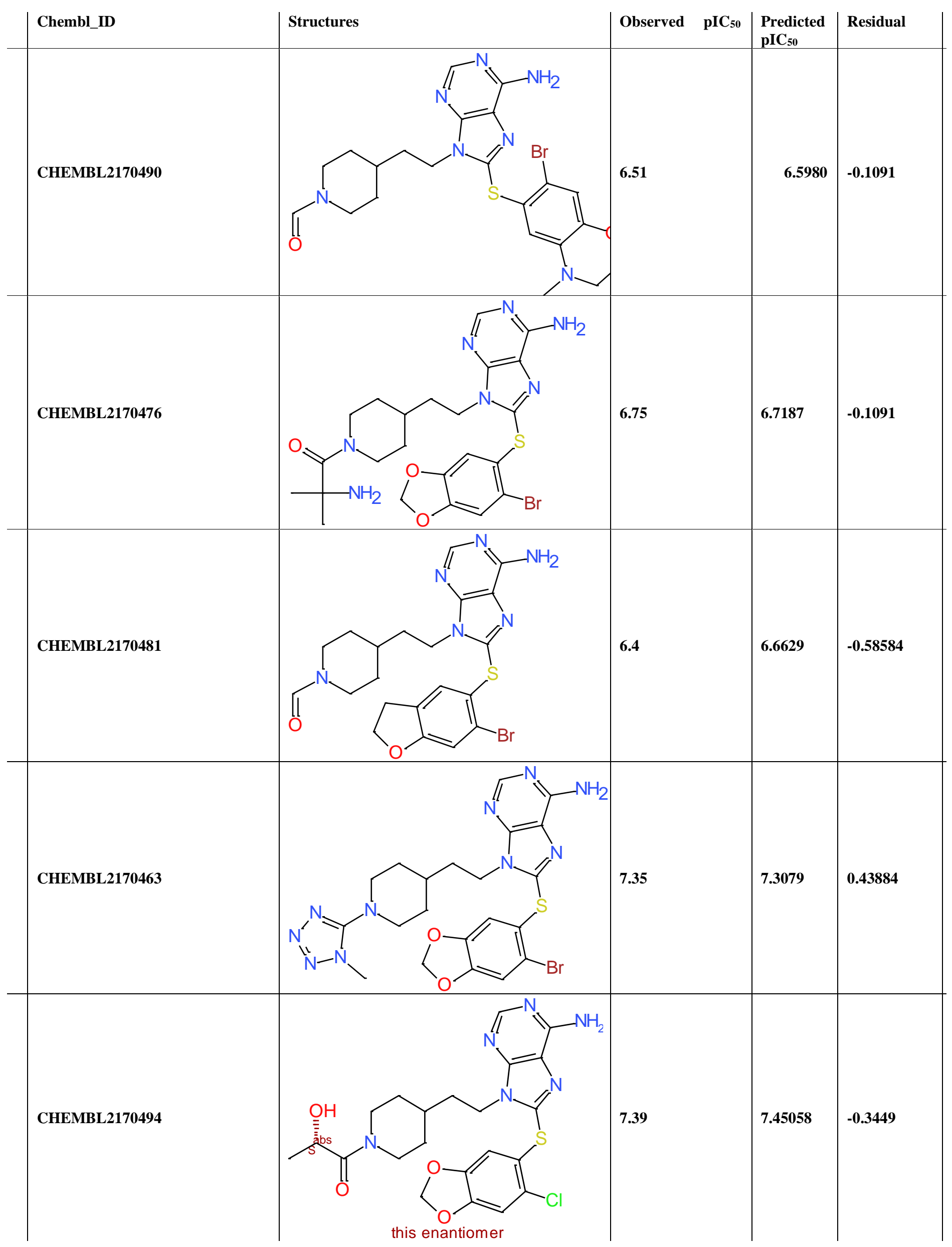




\begin{tabular}{|c|c|c|c|c|}
\hline Chembl_ID & Structures & Observed pIC $_{50}$ & $\begin{array}{l}\text { Predicted } \\
\text { pIC }_{50}\end{array}$ & Residual \\
\hline CHEMBL2170470 & & 6.19 & 6.5000 & -0.1507 \\
\hline CHEMBL2170469 & & 6.05 & 6.0658 & 0.00095 \\
\hline CHEMBL2170446 & & 6.85 & 6.8621 & 0.13780 \\
\hline CHEMBL2170451 & & 6.96 & 6.7632 & 0.36106 \\
\hline CHEMBL2170489 & & 7.52 & 7.5386 & -0.5163 \\
\hline
\end{tabular}




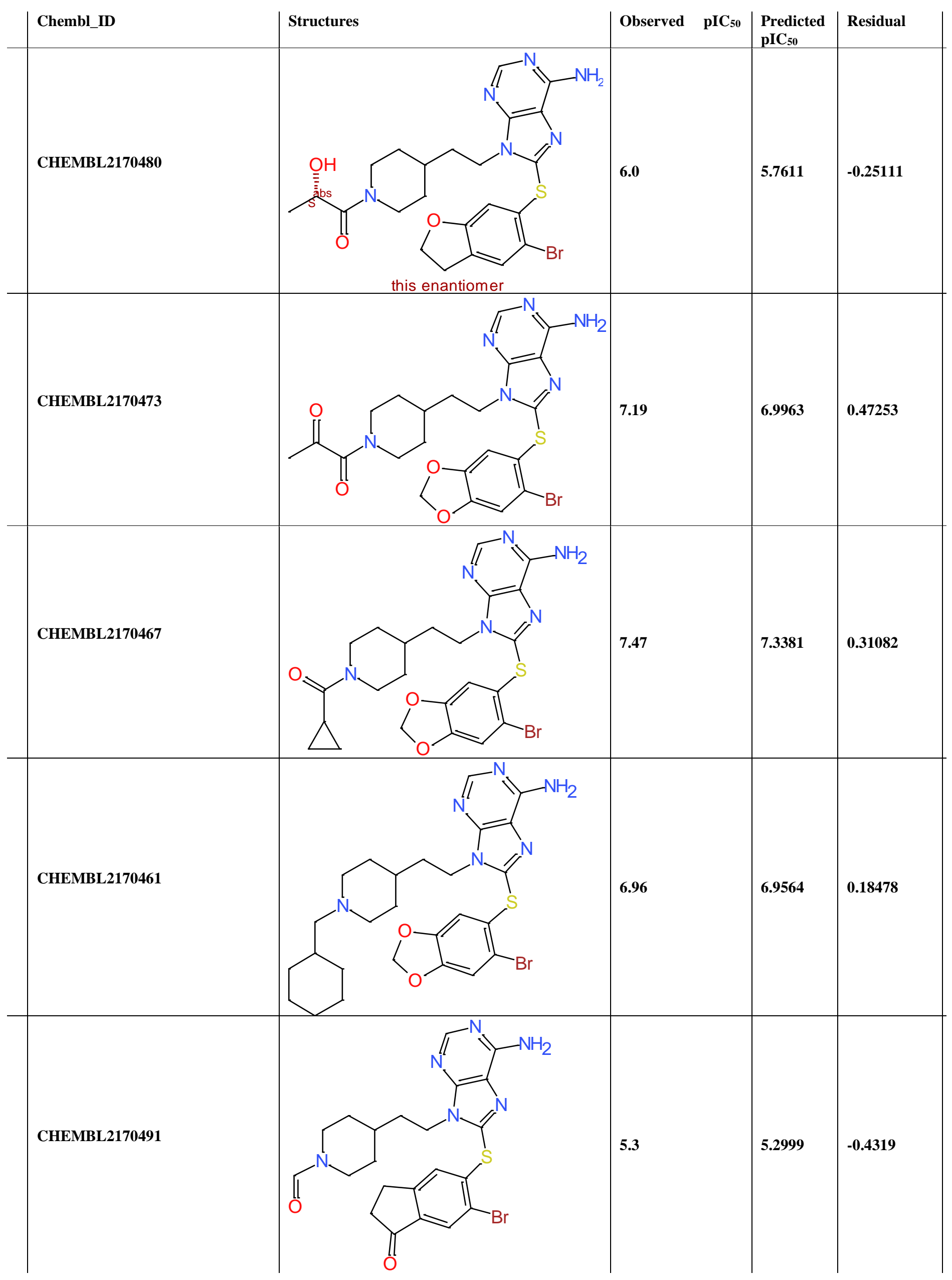




\begin{tabular}{|c|c|c|c|c|}
\hline Chembl_ID & Structures & Observed $\mathrm{pIC}_{50}$ & $\begin{array}{l}\text { Predicted } \\
\text { pIC }_{50}\end{array}$ & Residual \\
\hline CHEMBL2170448 & & 6.62 & 6.6057 & -0.0656 \\
\hline CHEMBL2170486 & & 7.22 & 7.1312 & 0.13989 \\
\hline CHEMBL2170454 & & 7.52 & 7.1417 & 0.24574 \\
\hline CHEMBL2170482 & & 7.22 & 7.1417 & 0.37761 \\
\hline CHEMBL2170457 & & 6.75 & 6.9272 & 0.02614 \\
\hline
\end{tabular}




\begin{tabular}{|c|c|c|c|c|}
\hline Chembl_ID & Structures & Observed $\mathrm{pIC}_{50}$ & $\begin{array}{l}\text { Predicted } \\
\text { pIC }_{50}\end{array}$ & Residual \\
\hline CHEMBL2170452 & & 6.22 & 6.3276 & -0.4667 \\
\hline CHEMBL2170456 & & 7.22 & 7.2867 & 0.15924 \\
\hline CHEMBL2170455 & & 6.6 & 6.6946 & -0.1108 \\
\hline CHEMBL2170453 & & 6.82 & 6.7343 & 0.16602 \\
\hline CHEMBL2170483 & & 7.1 & 7.2177 & 0.22341 \\
\hline
\end{tabular}




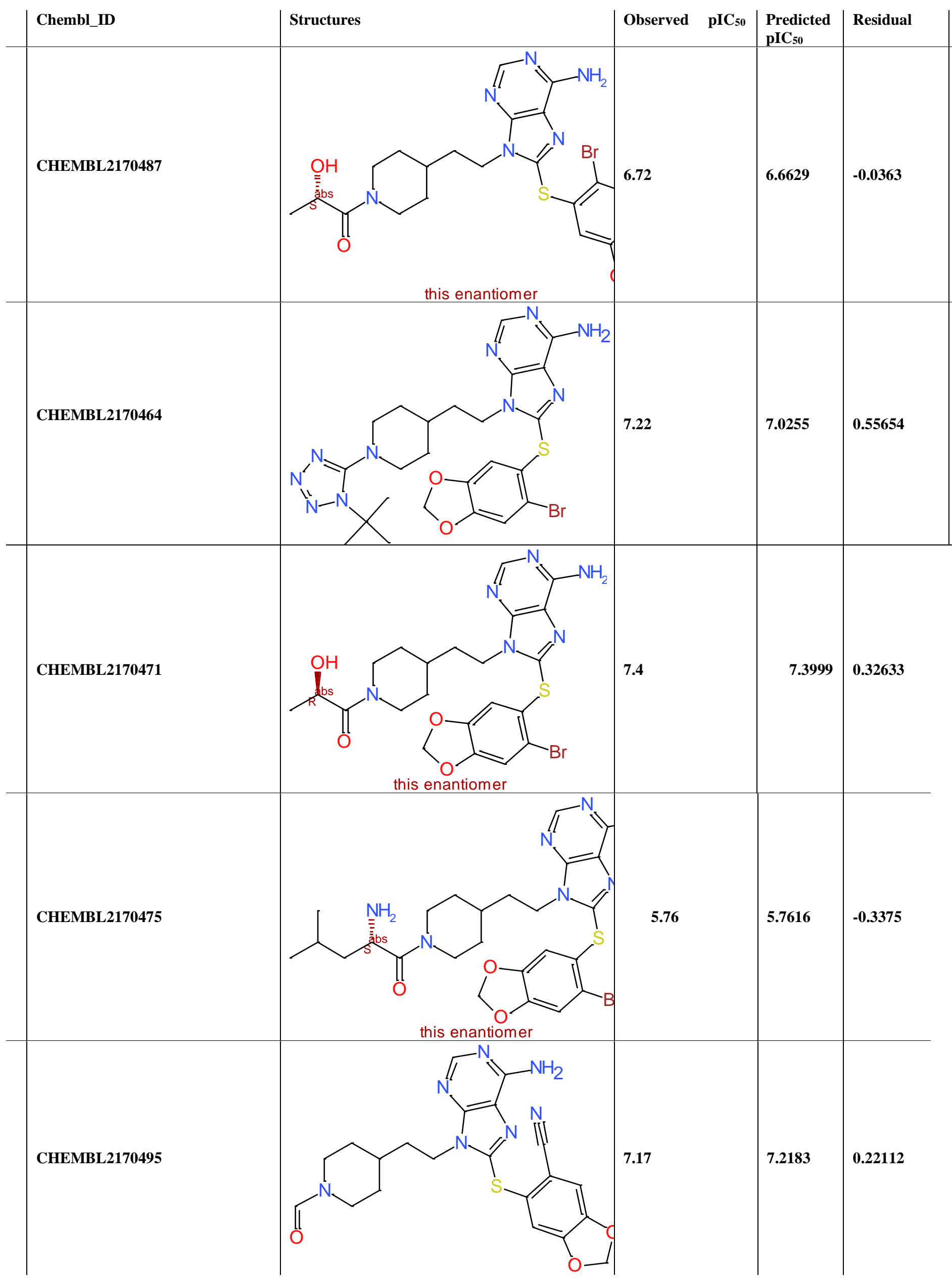

